\title{
Interventions on cognitions and perceptions that influence work participation of employees with chronic health problems: a scoping review
}

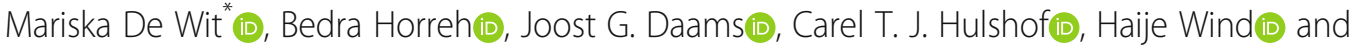

Angela G. E. M. de BoeriD

\begin{abstract}
Background: Cognitions and perceptions, such as motivation and return to work (RTW) expectations, can influence work participation of employees with chronic health problems. This makes these cognitions and perceptions important factors for occupational health professionals to intervene upon in order to increase work participation. There is, however, no overview of interventions that influence these factors and are aimed at increasing work participation. Therefore, the purpose of this scoping review is to explore available interventions that are focused on cognitions and perceptions of employees with chronic health problems and aimed at increasing work participation.

Methods: A scoping review was carried out following the framework of Arksey and O'Malley. Ovid MEDLINE and PsycINFO were searched for original papers published between January 2013 and June 2020. We included studies that describe interventions that focus on at least one of ten cognitions and perceptions and on work participation. The risk of bias of the studies included was assessed using quality assessment tools from the Joanna Briggs Institute.

Results: In total, 29 studies were identified that studied interventions aimed at changing at least one of ten cognitions and perceptions in order to change work participation. The interventions that were included mainly focused on changing recovery and RTW expectations, self-efficacy, feelings of control, perceived health, fear-avoidance beliefs, perceived work-relatedness of the health problem, coping strategies and catastrophizing. No interventions were found that focused on changing motivation or on optimism/pessimism. Four interventions were judged as effective in changing coping, self-efficacy, fear-avoidance beliefs, or perceived work-relatedness and work participation according to results of randomized controlled trials.
\end{abstract}

Conclusions: This review provides an overview of interventions that focus on changing cognitions and perceptions and work participation. Evidence was found for four effective interventions focused on changing these factors and increasing work participation. Occupational health professionals may use the overview of interventions to help employees with chronic health problems to increase their work participation.

Keywords: Occupational health professionals, Person-related factors, Cognitions, Perceptions, Return to work

\footnotetext{
*Correspondence: m.e.dewit@amsterdamumc.nl

Department of Public and Occupational Health, Coronel Institute of

Occupational Health, Amsterdam Public Health research institute, Amsterdam

UMC, University of Amsterdam, PO Box 22700, 1100

$\mathrm{DE}$, Amsterdam, The Netherlands
}

(c) The Author(s). 2020 Open Access This article is licensed under a Creative Commons Attribution 4.0 International License, which permits use, sharing, adaptation, distribution and reproduction in any medium or format, as long as you give appropriate credit to the original author(s) and the source, provide a link to the Creative Commons licence, and indicate if changes were made. The images or other third party material in this article are included in the article's Creative Commons licence, unless indicated otherwise in a credit line to the material. If material is not included in the article's Creative Commons licence and your intended use is not permitted by statutory regulation or exceeds the permitted use, you will need to obtain permission directly from the copyright holder. To view a copy of this licence, visit http://creativecommons.org/licenses/by/4.0/ The Creative Commons Public Domain Dedication waiver (http://creativecommons.org/publicdomain/zero/1.0/) applies to the data made available in this article, unless otherwise stated in a credit line to the data. 


\section{Background}

Occupational health professionals (OHPs) play an important role in increasing work participation in employees with chronic health problems. By OHPs, we refer to all professionals who make decisions about work participation or about receiving benefits for employees with health problems. In their practice it is important for them to focus on factors that may influence the work participation of these employees.

According to the International Classification of Functioning, Disability and Health (ICF model) different domains of factors can influence a person's work ability: disease-related factors, external factors and personal factors [1]. Personal factors that can influence work participation are cognitions and perceptions of employees [2-4]. In contrast to some other factors, cognitions and perceptions of employees are not always easy to recognize by OHPs. In addition, some employees may not even be aware that they have cognitions and perceptions that limit their work participation. In a study by De Wit et al. [2], six cognitions and perceptions were identified that were positively associated with work participation: positive recovery and return to work (RTW) expectations, optimism, self-efficacy, motivation, feelings of control, and perceived health. Four cognitions and perceptions were negatively associated with work participation: fear-avoidance beliefs, perceived work-relatedness of the health problem, limiting coping strategies and catastrophizing [2]. The association between these ten cognitions and perceptions and work participation makes them important targets for intervention.

To promote work participation in employees with chronic health problems, relevant cognitions and perceptions should be identified. Next, the hindering cognitions and perceptions should be limited and the positive cognitions and perceptions fostered [2].

To help employees who have cognitions and perceptions that can negatively influence work participation or to foster positive cognitions and perceptions, it is important for OHPs to get an overview of available interventions that may help to influence these factors. OHPs can recommend these interventions in order to increase work participation. However, as far as we know, no such a review about these interventions exists. Therefore, the purpose of this scoping review is to explore available interventions that are focused on at least one of the cognitions and perceptions and aimed at increasing work participation of employees with chronic health problems. The main question for this study is: Which interventions are available that are focused on cognitions and perceptions and aimed at increasing work participation of employees with chronic health problems?

\section{Methods}

\section{Methodology}

To answer our research question, we conducted a scoping review. We chose for a scoping review, because in contrast to a systematic review we do not have a focused research question on finding evidence for an association between variables. Instead, we have a broad and explorative research question about available interventions. In addition, we aim to summarize and disseminate our research findings to physicians and to consult physicians and patient representatives to get feedback on our findings, which is an essential component of scoping reviews [5].

We used the Joanna Briggs Institute Reviewers' Manual for methodology for Scoping Reviews [6] and the scoping review framework of Arksey and O'Malley [7] for conducting the review. This framework consists of six stages for conducting a scoping review: 1) identifying the research question, 2) identifying relevant studies, 3) study selection, 4) charting the data, 5) collating, summarizing and reporting the results, and 6) consultation. We used the PRISMA Extension for Scoping Reviews (PRISMAScR) Checklist for making sure that we reported all the relevant components of this scoping review [8].

\section{Identifying the research question}

The main question of this scoping review, as identified in the introduction is: Which interventions are available that are focused on cognitions and perceptions and aimed at increasing work participation of employees with chronic health problems?

\section{Identifying relevant studies}

The search strategy was developed with the help of a research librarian (JD). In order to find relevant words in titles and abstracts that can be used in the full search strategy, we first performed a limited search in Ovid MEDLINE to identify relevant articles. The complete search strategy consists of terms related to three elements of the PICO. In this review the population (P) are employees of working age (18-67 years) with chronic health problems. We defined chronic health problems according to the definition of the World Health Organization: Diseases with long duration and generally slow progression [9]. The interventions (I) in this review are interventions that focus on at least one of the ten cognitions and perceptions that are associated with work participation: expectations regarding recovery or RTW, optimism/pessimism, self-efficacy, motivation, feelings of control, perceived health, fear-avoidance beliefs, perceived work-relatedness, catastrophizing and coping strategies [2]. In this review, work participation is the outcome $(\mathrm{O})$, and this covers concepts such as RTW, sickness absence and current work status. With the full search strategy we looked for relevant articles in Ovid MEDLINE and PsycINFO. The two search strategies are presented in Additional file 1. 


\section{Inclusion criteria}

Only studies recently published, between January 1st 2013 and June 15th 2020, in peer-reviewed journals were included. Cohort studies, (randomized) controlled trials, and studies with pre-test post-test designs were included. Reference lists from relevant reviews and metaanalyses we found were screened for additional relevant studies. Articles were only considered eligible for inclusion if they were available in English or Dutch.

\section{Exclusion criteria}

Case studies and qualitative studies were excluded from this review. We also excluded articles in which participants are younger than 18 or older than 67 years, are students, are military personnel or veterans, are volunteers (no paid job) or are employees with substance abuse problems.

\section{Study selection}

For identifying and selecting relevant studies, we used the web application Rayyan [10]. The title and abstract of all records were independently screened on relevance based on previously identified inclusion and exclusion criteria by two reviewers (MdW and HW, MdW and $\mathrm{CH}, \mathrm{MdW}$ and $\mathrm{AdB}$ or $\mathrm{MdW}$ and $\mathrm{BH}$ ). For every excluded article, at least one reason for exclusion was reported by the researchers. If there was disagreement about possible relevance of these studies, the reasons for exclusion were discussed by the researchers until consensus was reached about inclusion or exclusion. If the researchers thought the article was potentially relevant, the full article was read and independently screened for relevance by two reviewers ( $\mathrm{MdW}$ and $\mathrm{BH}$ ). Disagreements about inclusion of the studies after reading the full text were discussed with all researchers until consensus was reached about inclusion or exclusion. The reference lists of reviews and meta-analyses that were found were independently screened for additional relevant studies by two reviewers and possible relevance of these studies was discussed (MdW and $\mathrm{BH}$ ).

\section{Charting the data}

For data charting we used a charting table drawn up by the research team. In this table, the following characteristics of the studies included in the review were described: first author, year of publication, country, study design, characteristics of study population (number of participants, mean age, gender, health status) and intervention types (duration, number and type of sessions, providers of the intervention, main components of the intervention). In addition, we described the cognitions and perceptions in that study, how they are measured and the follow-up period. Finally, we described the effect of the intervention on the cognition or perception of interest and on work participation. The data were charted by two researchers (MdW and $\mathrm{BH}$ ). All data charting was discussed between the two researchers until consensus was reached. After this, the other researchers (AdB, HW, CH) each checked one third of the dataextraction, so that all data were ultimately checked.

\section{Collating, summarizing and reporting the results}

We assessed the quality of the studies with the assessment instruments of the Joanna Briggs Institute, which has different criteria for different study types, and we presented the scores in tables [11]. The detailed characteristics of the studies are presented in the Additional file. We presented the effects of the interventions from the eligible studies per factor in two tables, one table for interventions that were studied in randomized controlled trials (RCTs) and one table for interventions that were studied with other study designs. In these tables we presented the health problems of the study population, the name and type of the intervention of interest, and the effect of the intervention on the cognition or perception and on work participation. We also reported whether, based on the findings in our review, the intervention should be recommended by OHPs.

\section{Consultation}

The last stage in the framework of Arksey and O'Malley [7] is the consultation of stakeholders. We consulted OHPs and a patient representative by e-mail or in a faceto-face meeting to obtain feedback on the findings. In the Netherlands the two important groups of OHPs are occupational physicians (OPs) and insurance physicians (IPs). OPs focus particularly on prevention of work-related diseases, health promotion, and in guiding employees with health problems in their RTW or in retaining work. IPs try to help to increase work participation in these employees by evaluating the functional abilities of the employee and by determining whether employees should receive a work disability benefit. We asked the OPs, IPs and patient representative about their experience with the interventions or components of the interventions and what to consider when a physician wants to recommend the interventions in daily practice. During the face-to-face meeting notes were made by the researcher (MdW). The most important notes and the answers by email were summarized by one researcher $(\mathrm{MdW})$ and checked by the other researchers (AdB, $\mathrm{CH}$, and $\mathrm{HW})$. We used the feedback from the OPs, IPs and patient representative to describe the implications for practice in order to make the results of this study more practical for OHPs.

\section{Results}

\section{Studies selected}

The search process is presented in Fig. 1. In total, 4429 studies were found in PsycINFO and 5520 studies in 


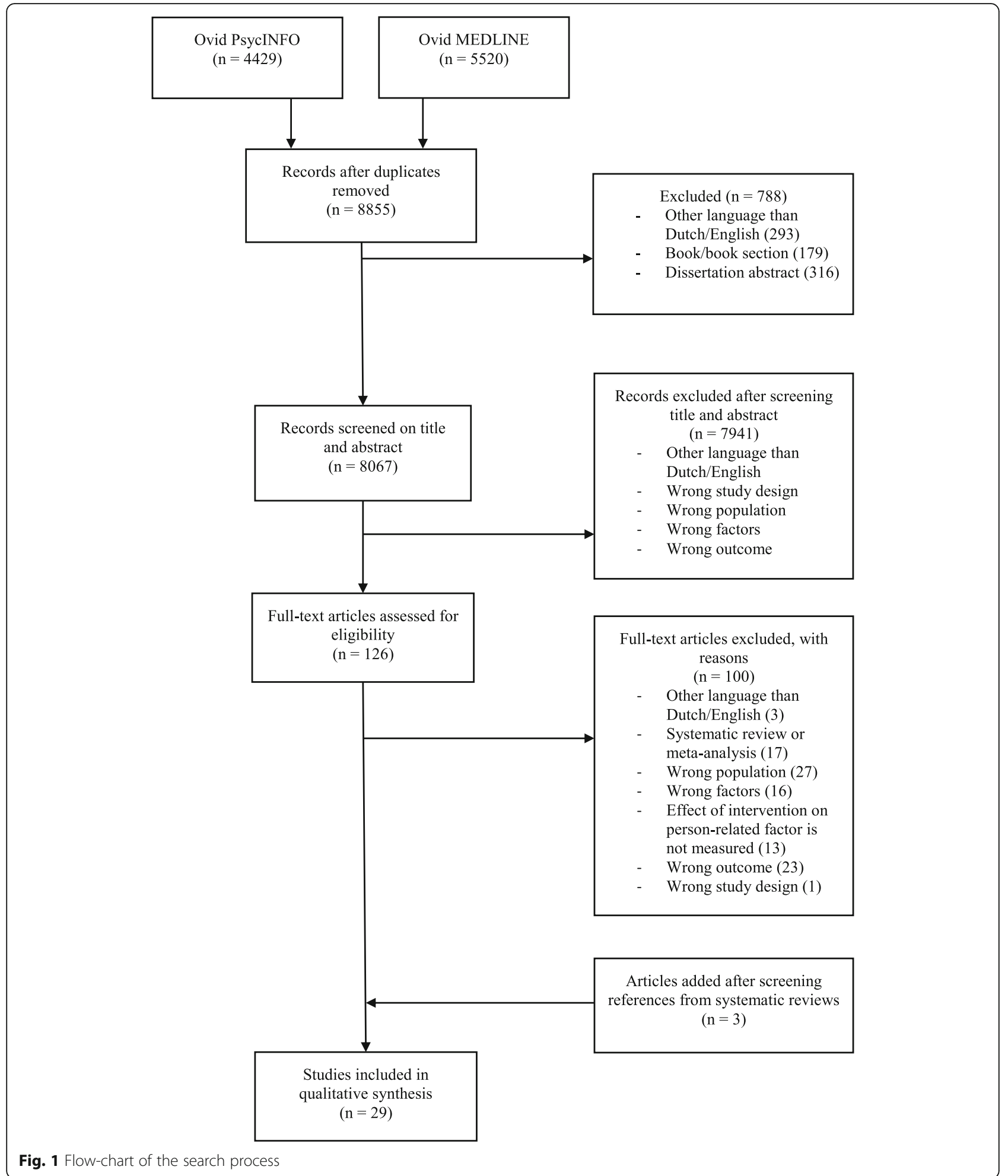

Ovid MEDLINE. Twenty-nine studies were included in this review. The final sample consisted of sixteen RCTs, nine cohort studies, three studies with a single group pre-test post-test design and one non-randomized experimental study.
Table 1 and Table 2 describe the effect of the interventions in question on cognitions and perceptions and on work participation. They also indicate whether OHPs should recommend the intervention to employees - a matter that remains unclear for a couple of interventions 


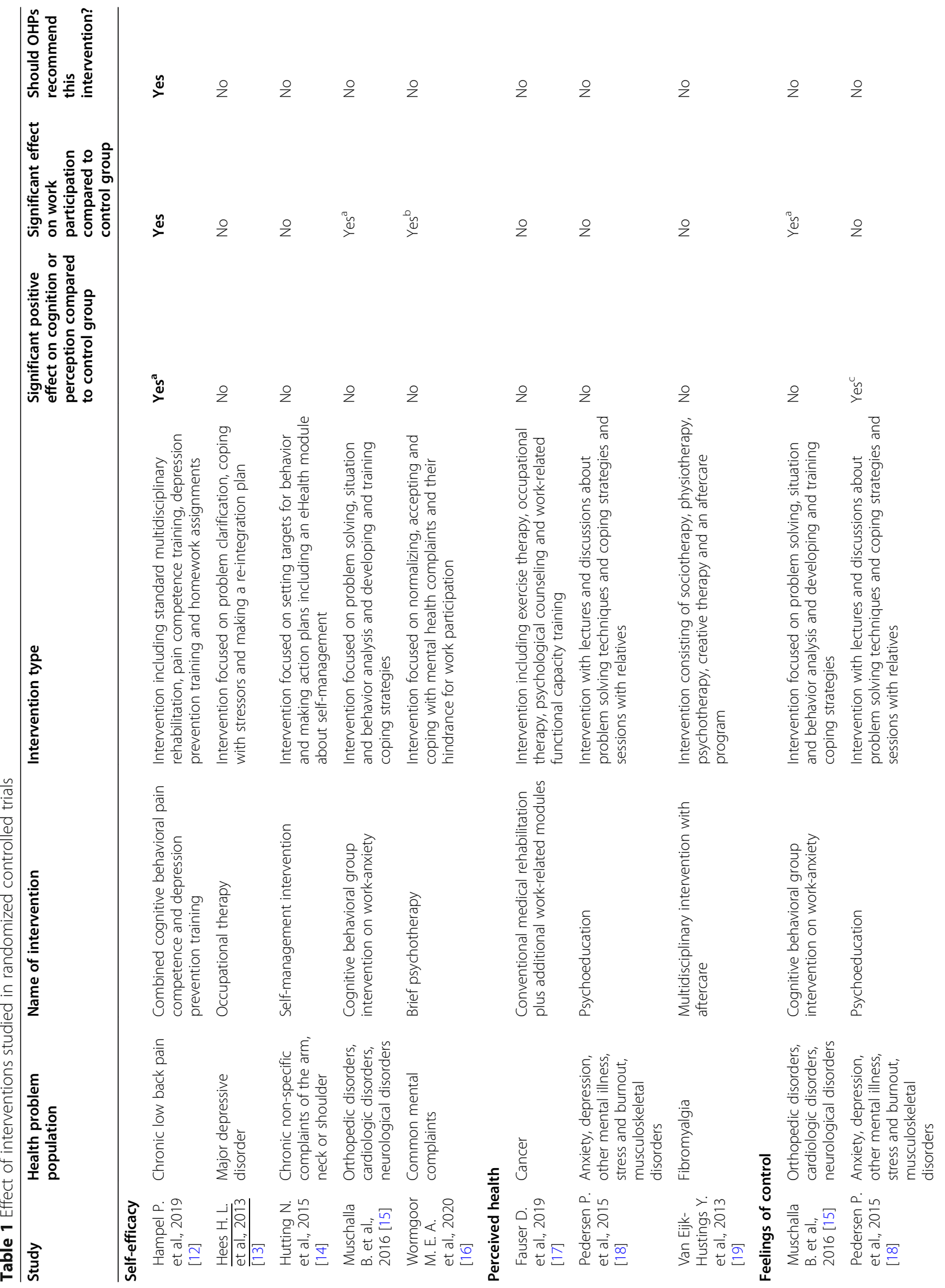




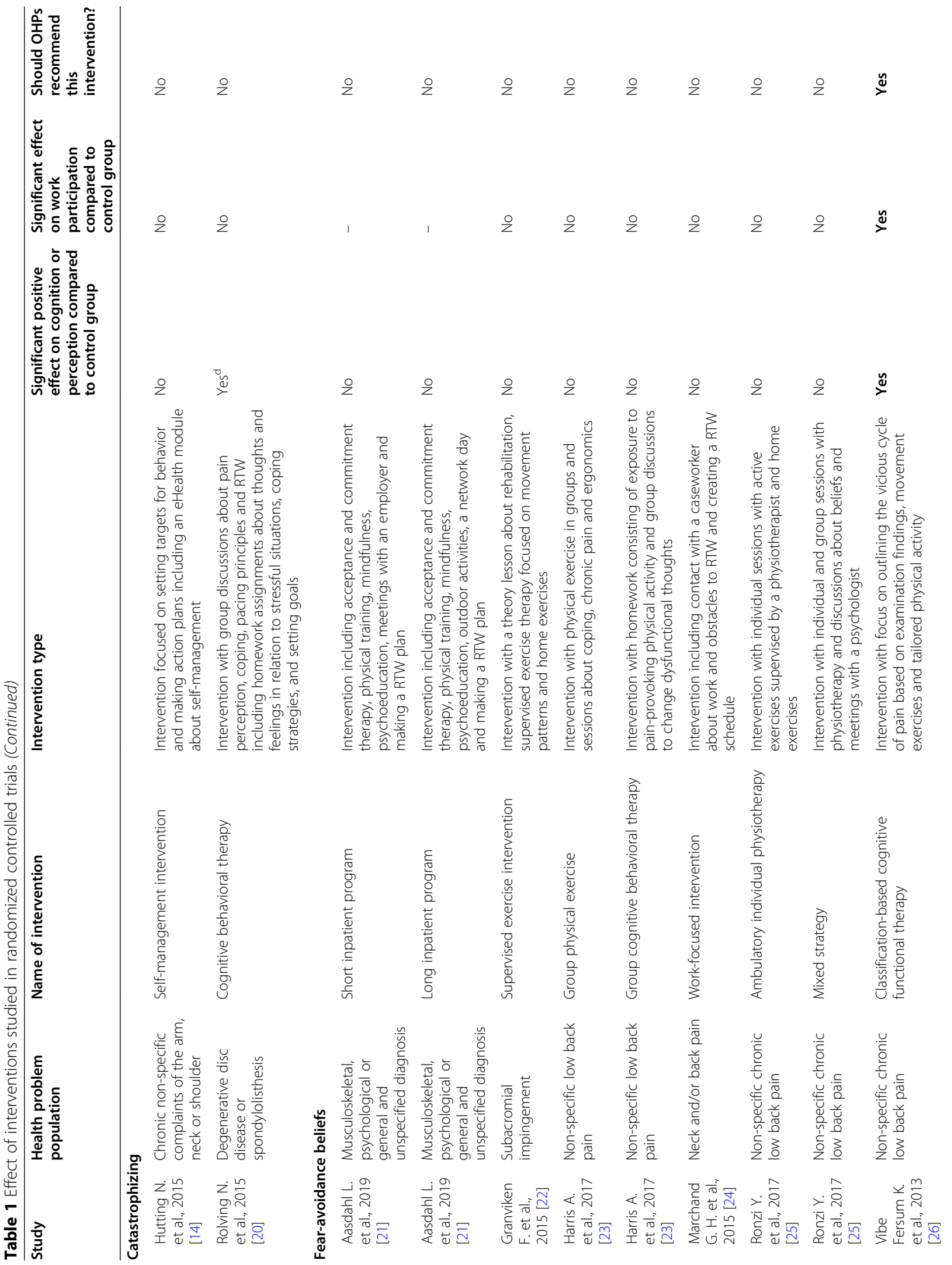




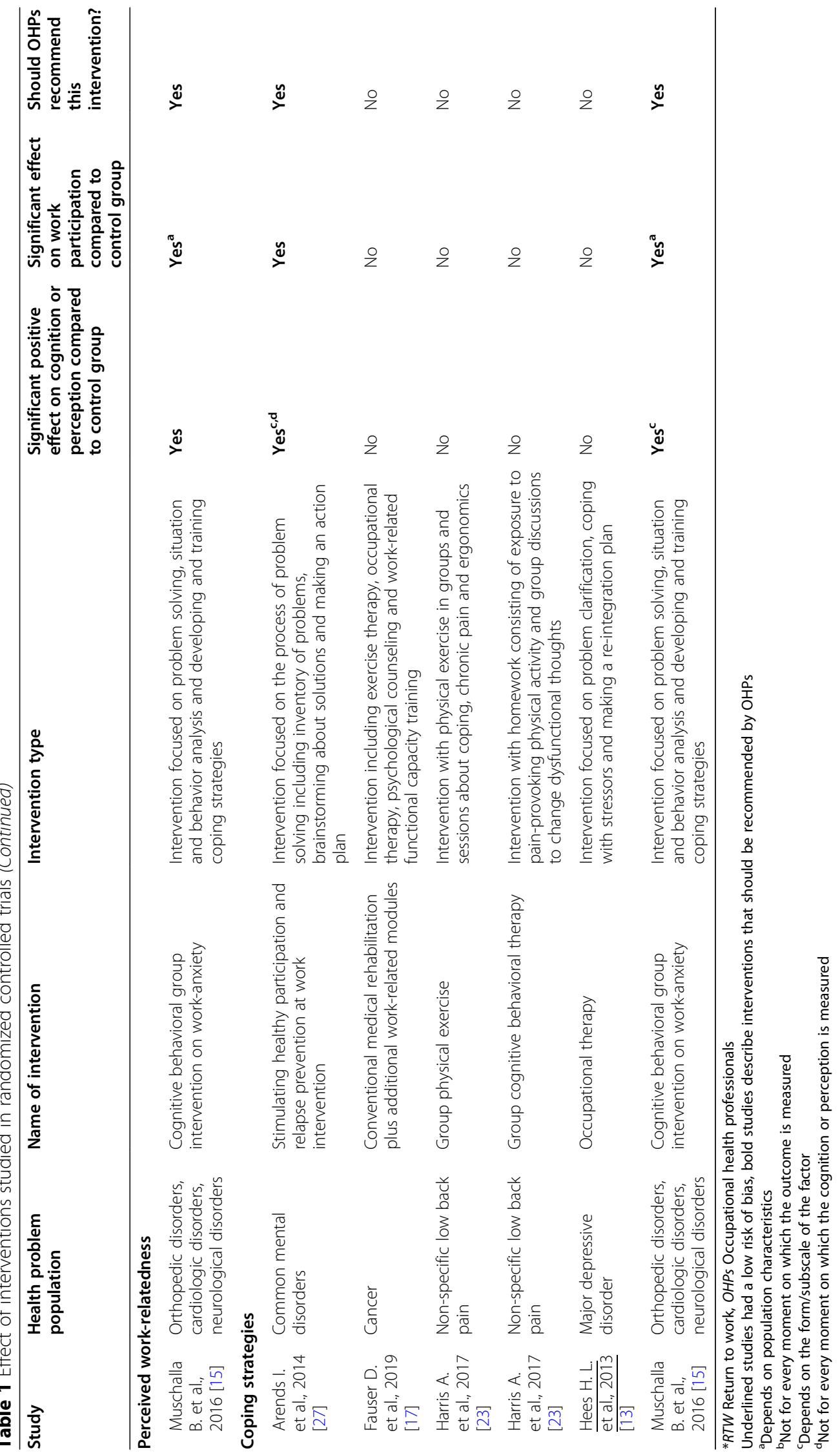




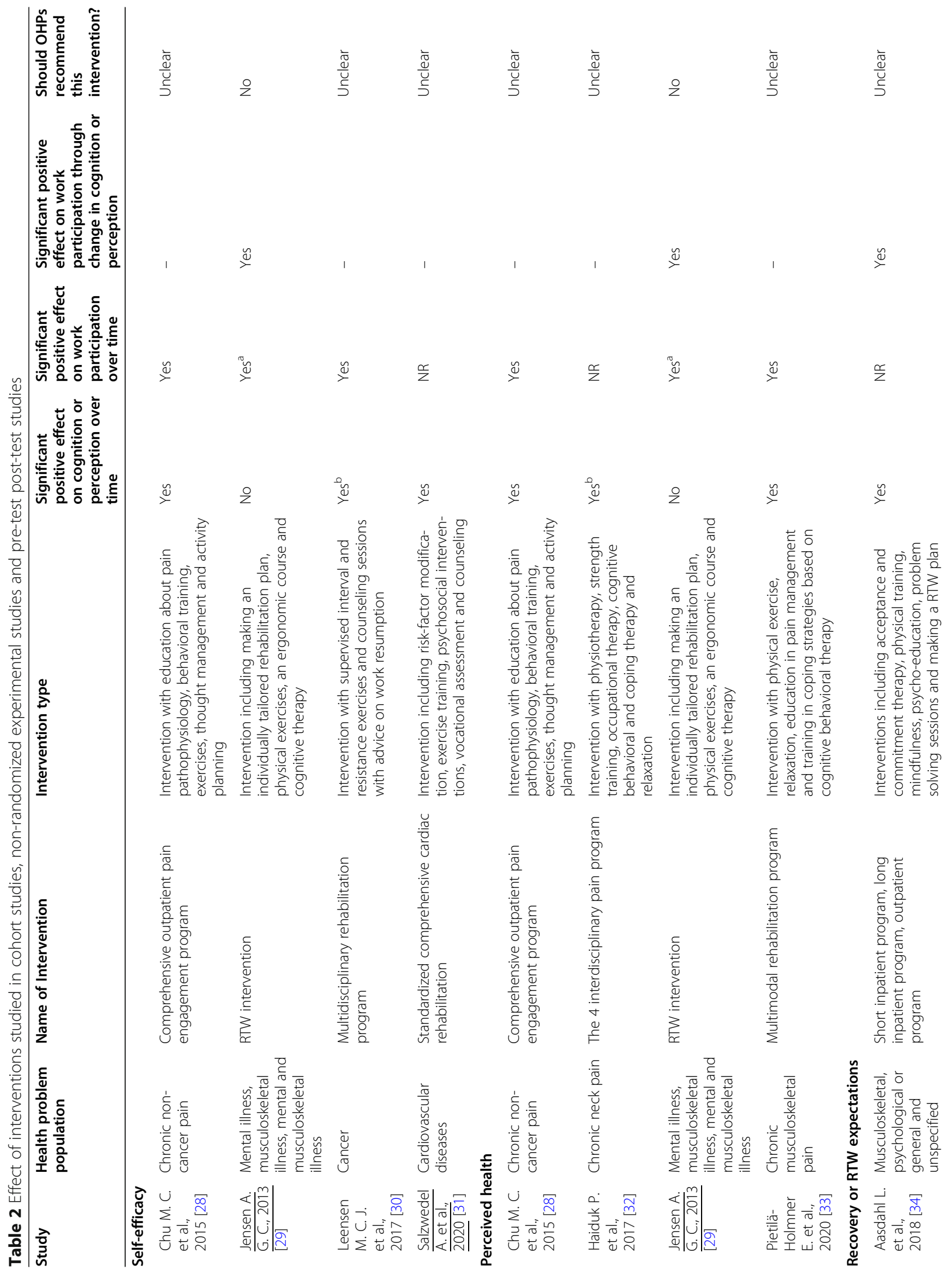




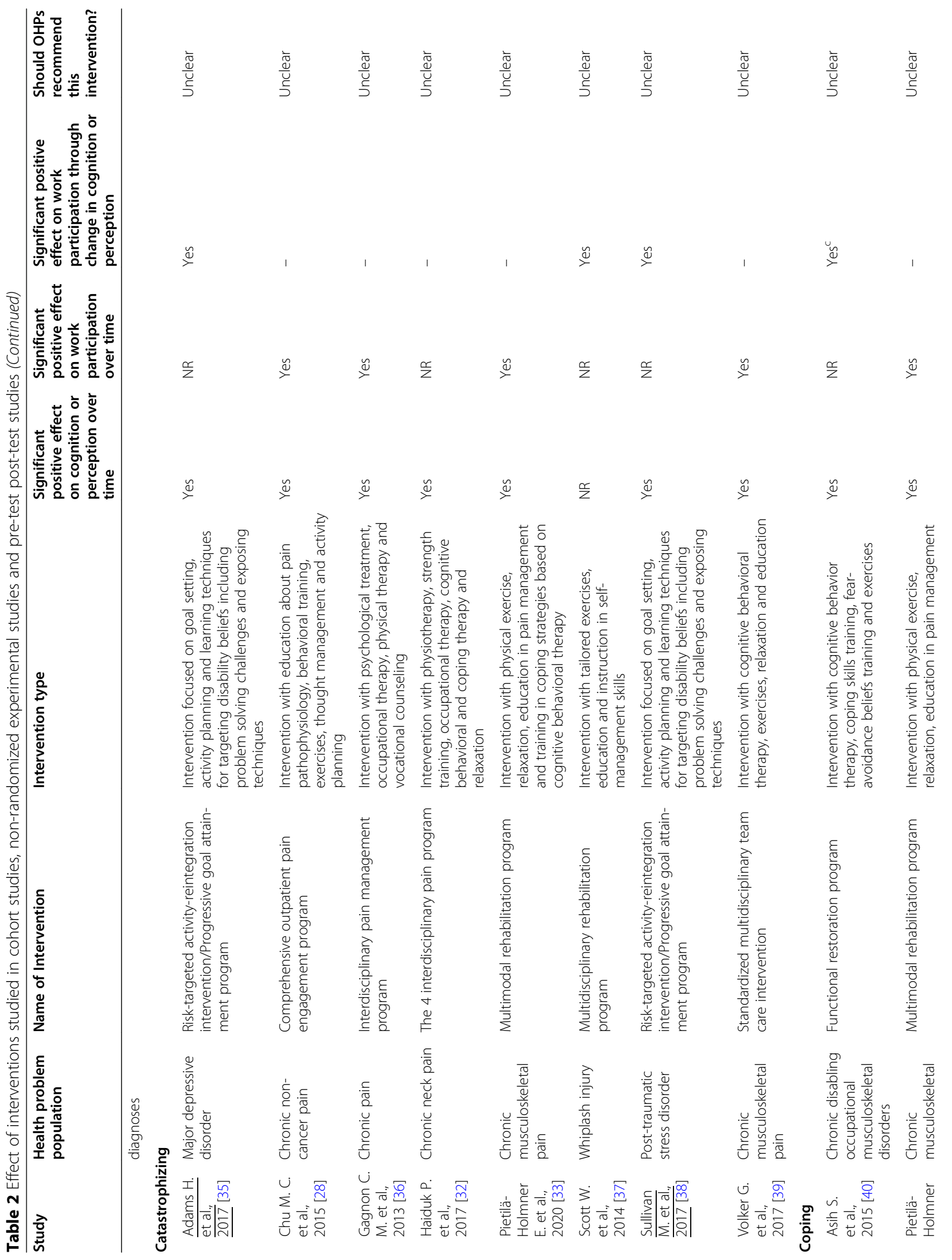




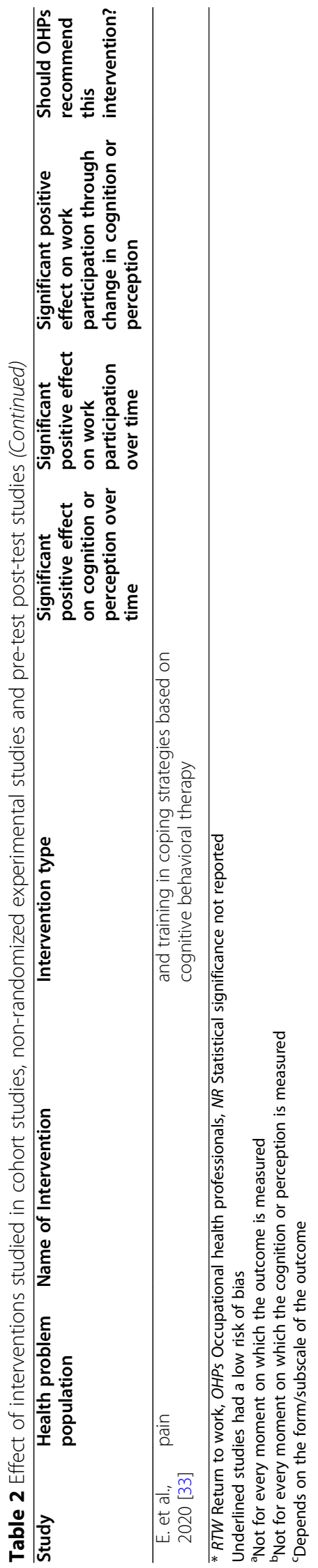


because the effects of the interventions are not compared between an intervention and a control group. Detailed characteristics of the final studies that were included in this review are presented in Additional file 2.

\section{Risk of bias}

Fifteen of the sixteen RCTs had a moderate risk of bias and one had a low risk of bias. Five of the cohort studies had a moderate risk of bias, one had a high risk of bias and three had a low risk of bias. Of the non-randomized experimental studies and single group pre-test post-test studies, there were three with a moderate risk of bias and one with a low risk of bias. Scores on each criterion of the quality assessment tools are presented in Additional file 3.

\section{Factors positively associated with work participation Self-efficacy}

Nine studies, of which five were RCTs, studied the effect of an intervention on self-efficacy and work participation [12-16, 28-31]. The RCT of Hees et al. [13], which was described in detail in Hees et al. [41], the RCT of Hutting et al. [14], the RCT of Muschalla et al. [15] and the RCT of Wormgoor et al. [16] did not show a significant effect on self-efficacy. Only the "Combined cognitive behavioral pain competence and depression prevention training" described in the RCT of Hampel et al. [12] increased self-efficacy in participants with chronic low back pain and high levels of depressive symptoms. This intervention also resulted in a decrease in days of sick leave and had a positive effect on employment status. The intervention consisted of eight group sessions focused on for example treating pain-related beliefs, pain management, enhancement of activities and social skills training. The cohort study by Chu et al. [28] among employees with non-cancer pain and the study of Leensen et al. [30] among employees with cancer both showed a positive effect on self-efficacy and on work participation. These interventions were multidisciplinary interventions, which included exercises from physiotherapists and sessions directed to activity planning or planning for gradually resuming work. The difference between these interventions was that one of them consisted mostly of individual sessions over a longer period of twelve weeks [30], while the other consisted of group sessions over a shorter period of fourteen days [28]. Although both studies showed a positive effect of the intervention on self-efficacy and on work participation, the researchers of these studies did not study whether change in work participation was caused by the change in self-efficacy. In addition, the intervention described by Salzwedel et al. [31] among employees with a cardiovascular disease had a positive effect on self-efficacy. However, the statistical significance of the effect on work status was not reported. The intervention in the study of Jensen [29] among employees with mental or musculoskeletal illness, which was more precisely described by Jensen [42], showed no effect on self-efficacy.

\section{Perceived health}

Seven studies, of which three RCTs, studied the effect of an intervention on perceived health and work participation [17-19, 28, 29, 32, 33]. The interventions of Pedersen et al. [18], Fauser et al. [17] and Van Eijk-Hustings et al. [19] did not have a significant effect on perceived health. The intervention in the cohort study of Chu et al. [28] on thought management and activity planning among employees with chronic non-cancer pain increased perceived health and improved the work status of employees. However, no results were reported regarding whether the increase in perceived health caused the increase in work participation. In addition, the intervention in the cohort of Pietilä-Holmner et al. [33] with physical exercise, education in pain management and training coping strategies, increased perceived health and decreased sick leave among employees with chronic musculoskeletal pain. However, they did not report whether the increase in perceived health caused the increase in work participation either. Also, the intervention in the study of Haiduk et al. [32] among employees with chronic neck pain showed a significant positive effect on perceived health after 60 months. It seemed to increase working capacity, although the statistical significance of this last effect was not reported. This intervention focused on strength training, occupational therapy, cognitive behavioral therapy and coping therapy. The intervention in a cohort study of Jensen [29] did not have a significant effect on perceived health.

\section{Recovery and RTW expectations}

One study of Aasdahl et al. [34] studied the effect of an intervention on RTW expectations and work participation among employees with different kinds of chronic diseases. The intervention involved acceptance and commitment therapy, physical training and psycho-education. This intervention significantly improved the expectations of employees regarding RTW. In this study, the improvement in these expectations was associated with sustainable RTW and more work participation days.

\section{Motivation}

No studies were found on interventions that were focused on motivation and aimed at increasing work participation.

\section{Optimism}

No studies were found on interventions that were focused on optimism or pessimism and aimed at increasing work participation. 


\section{Feelings of control}

Two RCTs with interventions focused on feelings of control and work participation were found $[15,18]$. The intervention of Muschalla et al. [15] did not have an effect on internal and external control perception. However, the intervention studied by Pedersen et al. [18], which was directed to problem solving techniques and coping strategies, did show that internal locus of control was higher for employees in the intervention group at three and six months follow-up in comparison with the control group. There were no differences in other locus of control variables. However, at three months, more participants in the control group than in the intervention group had full RTW, which indicates a negative effect of the intervention on work participation. There were no significant differences in RTW between the intervention and the control group at six or twelve months.

\section{Factors negatively associated with work participation Catastrophizing}

Most of the studies we found which focused on cognitions and perceptions and work participation were aimed at the factor catastrophizing. In total, ten studies were found that focused on this factor and work participation $[14,20,28,32,33,35-39]$. Among these studies there were two RCTs [14, 20]. None of the interventions that were studied in these randomized controlled trials (RCTs) had a positive effect on work participation. Only the cognitive behavioral therapy intervention of Rolving et al. [20] on pain perception, coping and pacing principles, among employees with degenerative disc disease or spondylolisthesis, which was further described in the study of Rolving et al. [43], decreased catastrophizing more in the intervention group than in de control group after six months, but not after three months and oneyear follow-up. All the interventions in the other studies $[28,32,33,35-39]$ seemed to decrease catastrophizing over time, although the significance of this decrease due to the intervention on self-management skills described by Scott et al. [37], was not reported. The interventions described by Chu et al. [28] among employees with chronic non-cancer pain, Gagnon et al. [36] among employees with chronic pain, Pietilä-Holmner et al. [33] among patients with chronic musculoskeletal pain and Volker et al. [39], which was among employees with chronic musculoskeletal pain as well, significantly increased work participation over time. All these interventions had group sessions with psychological components, such as psychological treatment, thought management and cognitive behavioral therapy, and physical components, such as pool therapy and physical exercises. The interventions of Volker et al. [39], PietiläHolmner et al. [33] and Chu et al. [28] contained relaxation exercises as well. The multidisciplinary intervention of Haiduk et al. [32] among employees with chronic neck pain, which contained components of strength training, occupational therapy, cognitive behavioral therapy and coping therapy, seemed to increase work participation as well, although the statistical significance of this effect is not reported. In addition, the studies of Adams et al. [35], Scott et al. [37], and Sullivan et al. [38], showed that a decrease in catastrophizing was associated with a higher rate of RTW or occupational reengagement. The "Risk-targeted activity-reintegration intervention" (or "Progressive goal attainment program") described by Adams et al. [35] and Sullivan et al. [38], which was further described in the article of Sullivan et al. [44], consisted of maximum ten sessions focused on goal setting, activity planning, learning specific techniques to target and reduce catastrophic thinking and exposing techniques to facilitate re-engagement in activities.

\section{Fear-avoidance beliefs}

Six RCTs were found about interventions focused on fear-avoidance beliefs and work participation [21-26]. Only one of the studied interventions had a significant effect on this factor and on work participation [26]. The "Classification-based cognitive functional therapy" studied by Vibe Fersum et al. [26] among employees with non-specific chronic low back pain significantly decreased fear-avoidance beliefs and decreased the number of sick leave days. This intervention contained components of movement exercises, tailored physical activity and was directed at outlining the vicious cycle of pain. None of the interventions in other studies showed a significant effect on fear-avoidance beliefs as compared to the control groups [21-25].

\section{Perceived work-relatedness}

One RCT of Muschalla et al. [15] was found with an intervention focused on perceived work-relatedness of the health problem and work participation. This intervention, which focused mainly on developing and training coping strategies among employees with orthopedic, cardiologic and neurological disorders, decreased perceived work-relatedness in the intervention group. The intervention also reduced the sick leave duration after six months for patients with work-anxiety, but not for the whole group of participants.

\section{Coping strategies}

Seven studies described interventions on coping strategies and work participation, of which five RCTs and two cohort studies $[13,15,17,23,27,33,40]$. The "Stimulating health participation and relapse prevention at work" intervention of Arends et al. [27] among employees with common mental disorders and the 
"Cognitive behavioral group intervention on workanxiety" of Muschalla et al. [15] among employees with orthopedic, cardiologic and neurological disorders changed coping and improved work participation. In the study of Arends et al. [27] on the effect of an intervention focused on the problem solving process, employees in the intervention group used the coping strategy distraction more often than the control group and had a lower incidence of recurrent sickness absence. However, there were no differences between the control group and intervention group in other coping strategies. In the study of Muschalla et al. [15], employees in the intervention group showed a significant increase in the coping strategies self-calming and self-instruction and showed a decrease in sick leave duration. This intervention was also directed at problem solving and contained training on strategies to cope with work-anxiety and situation and behavior analyses. The interventions studied in the RCTs by Harris et al. [23], Hees et al. [13] and Fauser et al. [17] did not significantly change coping or work participation. The intervention in the cohort study of Asih et al. [40] among employees with chronic musculoskeletal disorders significantly changed coping profiles. The intervention contained components of strength training, cognitive behavior therapy, coping skill training and fear-avoidance beliefs training. After the intervention, there were more adaptive copers and less dysfunctional copers or interpersonally distressed persons. There was a significant association between the coping profiles at discharge and work retention, but not with RTW rate. In addition, the "Multimodel rehabilitation program" described in the cohort study of Pietilä-Holmner et al. [33] seemed to change coping strategies. Employees who participated in the program scored higher in the coping strategy engagement and the coping strategy pain willingness and had a lower rate of sick leave 1 year after the intervention.

\section{Consultation with OPs, IPs and a patient representative}

Two OPs, two IPs and a patient representative were consulted to give feedback on the findings of this scoping review. The OPs and IPs recognized interventions or components of the interventions and had experience with recommending them to employees. The patient representative recognized components of interventions in the interventions she had followed.

We asked the OPs and IPs specifically about their experience with interventions on changing motivation and opti$\mathrm{mism} /$ pessimism, because on these factors no interventions had been identified in this scoping review. They were not aware of interventions on these factors either. However, they indicated that they would try to influence some cognitions and perceptions of employees, for example motivation and self-efficacy, by themselves during their consultations.
For choosing an intervention that they would recommend to employees in daily practice, they would, however, not only look at the effectiveness of the intervention. They also considered it very important to look at the type of client (e.g. level of education) and the disease or disorder he or she has, for choosing the right intervention. Some physicians mentioned the importance of deciding together with the employee which intervention is the best fit for the employee. The patient representative emphasized that her preference for one intervention above another is partially based on how much expertise the providers have with the interventions. Because in the Netherlands the employer has to pay for the intervention, the costs of the intervention, the amount of money the employer wants to invest in the employee and the reimbursement policies of insurance companies are all important for determining whether interventions are recommended or not. Some OPs and IPs mentioned that most of the time it is not one person-related factor, but multiple negative cognitions and perceptions that are present in employees, which could make it important to combine interventions or components of interventions.

\section{Discussion}

In this scoping review, we identified 29 studies, of which 23 with a moderate risk of bias, that studied interventions aimed at changing at least one of ten cognitions and perceptions in order to change work participation. The interventions included in the study mainly focused on changing recovery and RTW expectations, selfefficacy, feelings of control, perceived health, fearavoidance beliefs, perceived work-relatedness of the health problem, coping strategies and catastrophizing. We found no interventions on changing motivation or on optimism/pessimism.

From the results of this review, we can conclude that four interventions were effective in changing cognitions and perceptions and work participation, and can be recommended to employees by OHPs: The "Stimulating health participation and relapse prevention at work" intervention described by Arends et al. [27], the "Cognitive behavioral group intervention on work-anxiety" described by Muschalla et al. [15], the "Combined cognitive behavioral pain competence and depression prevention training" described by Hampel et al. [12] and "Classification-based cognitive functional therapy" described by Vibe Fersum et al. [26]. These interventions were effective in changing work participation by changing coping [15, 27], perceived work-relatedness [15], self-efficacy [12] or fear-avoidance beliefs [26]. Two of the four interventions [26, 27] involved individual sessions with employees and two interventions $[12,15]$ involved group sessions. 
The four interventions that were effective in changing cognitions and perceptions and in increasing work participation had only one main provider, and this was an occupational physician [27], psychological therapist [12, 15] or physiotherapist [26]. This is in contrast to a review of Hoefsmit et al. [45] in which they conclude that it is especially multidisciplinary interventions in which multiple professionals are involved, that seem effective in increasing work participation. However, as we looked at the effectiveness of the intervention on work participation and on one specific cognition or perception, it might not be surprising that it was especially monodisciplinary interventions that seem to be effective. Besides, many multidisciplinary interventions that were found in this scoping review were studied in cohort studies instead of RCTs. From these studies we cannot conclude whether the interventions are effective or not because they do not compare the change in the cognitions and perceptions and work participation between an intervention and a control group, while many of these interventions seemed to change cognitions and perceptions and work participation over time. An example of this is the intervention of Asih et al. [40], which changed coping profiles over time, which, in turn, had a positive effect on the work retention rate. Therefore, it is possible that more of the described interventions in this scoping review are effective, but that the effectiveness has just not been studied in RCTs yet.

Some of the interventions found in this scoping review which were specifically aimed at one person-related factor also had effects on other person-related factors. For example, the intervention of Muschalla et al. [15] on developing and training coping strategies also had an effect on perceived work-relatedness. This could indicate that some of the cognitions and perceptions are related to other cognitions and perceptions. This is in line with a study by Petrie and Weinmann [46] and a study of Woodhouse et al. [47], which describe that illness perceptions, such as beliefs about the cause of the illness, can influence coping strategies. It might be that changing one cognition or perception could have an effect on another cognition or perception as well.

For certain cognitions and perceptions, no interventions were found at all. This was the case for the factors motivation and optimism/pessimism. The OPs and IPs we approached did not know interventions specifically aimed at these cognitions and perceptions either. However, they did mention that they sometimes try to influence the cognitions and perceptions (such as motivation) of the employees during their consultations without implementing a specific intervention. This is in line with the results of two studies of Müssener et al. $[48,49]$ in which patients said that encounters with physicians could affect different cognitions and perceptions, such as motivation. So, it is possible that some cognitions and perceptions could also be affected during consultations.

\section{Strengths and limitations}

This review provides an overview of interventions aimed at changing cognitions and perceptions and work participation. OPs, IPs and other OHPs can use this overview to get an indication of which intervention they should recommend in order to increase work participation in employees with chronic health problems. We followed all the steps of the framework of Arksey and O'Malley [7] for conducting this scoping review including the essential last step as described by Levac et al. [5] in which we consulted important stakeholders (e.g. OPs, IPs and a patient representative). This provided additional information into the factors that we should keep in mind when putting these findings into practice, such as the costs and the target audience of the intervention.

A limitation of this review might be that some interventions are tested on specific groups, for example on employees with depression [13, 35]. It is possible that cognitions and perceptions are different between groups. For example, fear-avoidance beliefs can be a factor that is more often present in people who experience pain than in people with other health problems. In addition, components of some interventions are not applicable to employees with other health problems. For example, in the interventions described by Harris et al. [23] participants get homework assignments with exposure to painprovoking physical activity. This component of the intervention is not applicable for employees who do not have pain when they are physically active. Therefore, the question remains how generalizable the results of studies on interventions tested on specific groups are to a broader population or employees with other health problems. Another limitation is that although the results show effectiveness of some interventions on changing cognitions and perceptions and changing work participation, it remains unclear which part or component of the intervention does have an actual effect on the personrelated factor. This is especially the case for multidisciplinary interventions that focus on many different aspects.

\section{Implications for practice and future research}

This review provides an overview of interventions that focus on changing cognitions and perceptions and work participation. OHPs may use the overview of interventions to help employees with chronic health problems to increase work participation.

Many of the identified interventions were not proven effective. Therefore, more studies, and especially more RCTs with a low risk of bias, are needed to study how hindering cognitions and perceptions can be limited and positive cognitions and perceptions fostered. In addition feasibility 
studies are needed to assess the practicality of the different interventions. Because many of the interventions included in the review are multidisciplinary interventions that focus on many different aspects and are also tested on different groups of employees, it is also important to study which component of the interventions actually helps for which group of employees. According to the consulted stakeholders the expertise of the intervention provider, the type of client (e.g. level of education) and the disease or disorder he or she has are very important to consider when recommending interventions. Results of research assessing which intervention components work for whom, may contribute to the development of more effective and efficient interventions to increase work participation. Finally, research is needed to determine whether these newly developed interventions actually could improve work participation and whether they are cost-effective, because costs are a very important aspect for OHPs in determining whether they should recommend an intervention according to the consulted stakeholders.

\section{Conclusion}

In conclusion, 29 studies were found which described interventions that focused on cognitions and perceptions and were aimed at increasing work participation. Four of these interventions $[12,15,26,27]$ are proven to be effective in RCTs and could be recommended by OHPs to employees in order to change cognitions and perceptions and increase work participation. However, most studies that were included had a moderate risk of bias, so caution should be used when recommending these interventions towards employees. More RCTs with a low risk of bias are needed to explore which of these and other promising interventions that were studied in other study designs are most effective (generally and in terms of costs). In addition more studies are needed to explore which components work for whom in order to increase the generalizability of the findings.

\section{Supplementary information}

Supplementary information accompanies this paper at https://doi.org/10. 1186/s12889-020-09621-5.

Additional file 1: Table 1. Ovid MEDLINE search strategy. Table 2.

Ovid PsycINFO search strategy.

Additional file 2: Table 1. Details of included studies.

Additional file 3: Table 1. Risk of bias of randomized controlled trials. Table 2. Risk of bias of cohort studies. Table $\mathbf{3}$. Risk of bias of nonrandomized experimental studies and studies with a single group pretest post-test design.

\section{Abbreviations}

RTW: Return to work; OHPs: Occupational health professionals; OPs: Occupational physicians; IPs: Insurance physicians; PRISMA-ScR: PRISMA Extension for Scoping Review; RCT: Randomized controlled trial

\section{Acknowledgements}

Preliminary results of this study were presented at the International Conclave on Occupational Health in Mumbai in January 2020 [50].

\section{Authors' contributions}

$J \mathrm{D}, \mathrm{MdW}, \mathrm{AdB}, \mathrm{CH}$ and HW contributed to developing the search strategy. MdW, HW, CH, BH and AdB screened the title and abstract of the records. MdW and BH screened the full articles. MdW, BH, AdB, HW and $\mathrm{CH}$ all contributed to the data-extraction process. All authors contributed to writing this article. The authors read and approved the final manuscript.

\section{Funding}

This study was funded by Instituut Gak (Grant number: 2016-757). The study sponsor had no role in the study design, collection, analysis, and

interpretation of data and in writing the report.

\section{Availability of data and materials \\ Not applicable.}

Ethics approval and consent to participate

Not applicable.

\section{Consent for publication}

Not applicable.

\section{Competing interests}

The authors declare that they have no competing interests.

Received: 11 September 2019 Accepted: 28 September 2020

Published online: 27 October 2020

\section{References}

1. World Health Organization. International classification of functioning, disability and health. Geneva: World Health Organization; 2001.

2. De Wit M, Wind H, Hulshof CTJ, Frings-Dresen MHW. Person-related factors associated with work participation in employees with health problems: a systematic review. Int Arch Occup Environ Health. 2018;91(5):497-512. https://doi.org/10.1007/s00420-018-1308-5.

3. Clay FJ, Newstead SV, McClure RJ. A systematic review of early prognostic factors for return to work following acute orthopaedic trauma. Injury. 2010; 41:787-803. https://doi.org/10.1016/j.injury.2010.04.005.

4. Besen $E$, Young $A E$, Shaw WS. Returning to work following low back pain: towards a model of individual psychosocial factors. J Occup Rehabil. 2015; 25:25-37. https://doi.org/10.1007/s10926-014-9522-9.

5. Levac D, Colquhoun H, O'Brien KK. Scoping studies: advancing the methodology. Implement Sci. 2010;5:69. https://doi.org/10.1186/1748-5908-5-69.

6. Joanna Briggs Institute. Joanna Briggs Institute Reviewers' Manual: 2015 edition / Supplement. In: Methodology for JBI Scoping Reviews. Adelaide: Joanna Briggs Institute; 2015.

7. Arksey H, O'Malley L. Scoping studies: towards a methodological framework. Int J Soc Res Mehodol. 2005;8(1):19-32. https://doi.org/10.1080/ 1364557032000119616.

8. Tricco AC, Lillie E, Zarin W, O'Brien KK, Colquhoun H, Levac D, et al. PRISMA extension for scoping reviews (PRISMA-SCR): checklist and explanation. Ann Intern Med. 2018;169:467-73. https://doi.org/10.7326/M18-0850.

9. www.who.int [Internet]. Geneva: World Health Organization [updated 2013 March; cited 2020 june]. Available from: http://www.who.int/features/ factfiles/noncommunicable_diseases/en/.

10. Ouzzani M, Hammady H, Fedorowicz Z, Elmagarmid A. Rayyan — a web and mobile app for systematic reviews. Syst Rev. 2016;5(1):210. https://doi.org/ 10.1186/s13643-016-0384-4.

11. Joanna Briggs Institute. Joanna Briggs Institute Reviewers' Manual: 2014 edition. Adelaide: Joanna Briggs Institute; 2014.

12. Hampel P, Köpnick A, Roch S. Psychological and work-related outcomes after inpatient multidisciplinary rehabilitation of chronic low back pain: a prospective randomized controlled trial. BMC Psychol. 2019;7(1):6. https:// doi.org/10.1186/s40359-019-0282-3.

13. Hees HL, de Vries G, Koeter MW, Schene AH. Adjuvant occupational therapy improves long-term depression recovery and return-to-work in good health in sick-listed employees with major depression: results of a randomised 
controlled trial. Occup Environ Med. 2013;70(4):252-60. https://doi.org/10. 1136/oemed-2012-100789.

14. Hutting N, Staal JB, Engels JA, Heerkens YF, Detaille SI. Nijhuis-van der Sanden MW. Effect evaluation of a self-management programme for employees with complaints of the arm, neck or shoulder: a randomised controlled trial. Occup Environ Med. 2015;72(12):852-61. https://doi.org/10. 1136/oemed-2015-103089.

15. Muschalla $B$, Linden $M$, Jöbges $M$. Work-anxiety and sickness absence after a short inpatient cognitive behavioral group intervention in comparison to a recreational group meeting. J Occup Environ Med. 2016;58(4):398-406. https://doi.org/10.1097/JOM.0000000000000678.

16. Wormgoor MEA, Indahl A, Andersen E, Egeland J. Effectiveness of briefer coping-focused psychotherapy for common mental complaints on workparticipation and mental health: a pragmatic randomized trial with 2-year follow-up. J Occup Rehabil. 2020;30(1):22-39. https://doi.org/10.1007/ s10926-019-09841-6.

17. Fauser D, Wienert J, Zomorodbakhsch B, Schmielau J, Biester I, Krüger HU, et al. Work-related medical rehabilitation in cancer: a cluster-randomized multicenter study. Dtsch Ärztebl Int. 2019;116(35-36):592. https://doi.org/10. 3238/arztebl.2019.0592

18. Pedersen P, Søgaard HJ, Labriola M, Nohr EA, Jensen C. Effectiveness of psychoeducation in reducing sickness absence and improving mental health in individuals at risk of having a mental disorder: a randomised controlled trial. BMC Public Health. 2015;15(1):763. https://doi.org/10.1186/ s12889-015-2087-5.

19. van Eijk-Hustings Y, Kroese M, Tan F, Boonen A, Bessems-Beks M, Landewé R. Challenges in demonstrating the effectiveness of multidisciplinary treatment on quality of life, participation and health care utilisation in patients with fibromyalgia: a randomised controlled trial. Clin Rheumatol. 2013;32(2):199-209. https://doi.org/10.1007/s10067-012-2100-7.

20. Rolving N, Nielsen CV, Christensen FB, Holm R, Bünger CE, Oestergaard LG. Does a preoperative cognitive-behavioral intervention affect disability, pain behavior, pain, and return to work the first year after lumbar spinal fusion surgery? Spine. 2015;40(9):593-600. https://doi.org/10.1097/BRS. 0000000000000843.

21. Aasdahl L, Marchand GH, Vasseljen O, Johnsen R, Fimland MS. Changes in fear-avoidance beliefs and work participation after occupational rehabilitation for musculoskeletal-and common mental disorders: secondary outcomes of two randomized clinical trials. J Rehabil Med. 2019;51(3):17582. https://doi.org/10.2340/16501977-2520.

22. Granviken F, Vasseljen $\mathrm{O}$. Home exercises and supervised exercises are similarly effective for people with subacromial impingement: a randomised trial. Aust J Phys. 2015;61(3):135-41. https://doi.org/10.1016/j.jphys.2015.05. 014.

23. Harris A, Moe TF, Eriksen HR, Tangen T, Lie SA, Tveito TH, et al. Brief intervention, physical exercise and cognitive behavioural group therapy for patients with chronic low back pain (the CINS trial). Eur J Pain. 2017;21(8): 1397-407. https://doi.org/10.1002/ejp.1041.

24. Marchand GH, Myhre K, Leivseth G, Sandvik L, Lau B, Bautz-Holter E, et al. Change in pain, disability and influence of fear-avoidance in a work-focused intervention on neck and back pain: a randomized controlled trial. BMC Musculoskelet Disord. 2015;16(1):94. https://doi.org/10.1186/s12891-0150553-y.

25. Ronzi Y, Roche-Leboucher G, Begue C, Dubus V, Bontoux L, Roquelaure Y, et al. Efficiency of three treatment strategies on occupational and quality of life impairments for chronic low back pain patients: is the multidisciplinary approach the key feature to success? Clin Rehabil. 2017;31(10):1364-73. https://doi.org/10.1177/0269215517691086.

26. Vibe Fersum K, O'Sullivan P, Skouen JS, Smith A, Kvåle A. Efficacy of classification-based cognitive functional therapy in patients with nonspecific chronic low back pain: a randomized controlled trial. Eur J Pain. 2013;17(6):916-28. https://doi.org/10.1002/j.1532-2149.2012.00252.x.

27. Arends I, van der Klink JJ, van Rhenen W, de Boer MR, Bültmann U. Prevention of recurrent sickness absence in workers with common mental disorders: results of a cluster-randomised controlled trial. Occup Environ Med. 2014;71(1):21-9. https://doi.org/10.1136/oemed-2013-101412.

28. Chu MC, Law RK, Cheung LC, Ma ML, Tse EY, Wong TC, et al. Pain management programme for Chinese patients: a 10-year outcome review. Hong Kong Med J. 2015;21(4):304-9. https://doi.org/10.12809/hkmj144350.

29. Jensen AGC. A two-year follow-up on a program theory of return to work intervention. Work. 2013;44(2):165-75. https://doi.org/10.3233/WOR-121497.
30. Leensen MCJ, Groeneveld IF, Van Der Heide I, Rejda T, Van Veldhoven PL, Van Berkel $\mathrm{S}$, et al. Return to work of cancer patients after a multidisciplinary intervention including occupational counselling and physical exercise in cancer patients: a prospective study in the Netherlands. BMJ Open. 2017; 7(6)::014746. https://doi.org/10.1136/bmjopen-2016-014746.

31. Salzwedel A, Koran I, Langheim E, Schlitt A, Nothroff J, Bongarth C, et al. Patient-reported outcomes predict return to work and health-related quality of life six months after cardiac rehabilitation: results from a German multiCentre registry (OutCaRe). PLoS One. 2020;15(5):e0232752. https://doi.org/10. 1371/journal.pone.0232752.

32. Haiduk P, Benz T, Lehmann S, Gysi-Klaus F, Aeschlimann A, Michel BA, et al. Interdisciplinary rehabilitation after whiplash injury: an observational prospective 5 years outcome study. Medicine. 2017;96(9):e6113. https://doi. org/10.1097/MD.0000000000006113.

33. Pietilä-Holmner E, Enthoven P, Gerdle B, Molander P, Stålnacke BM. Long-term outcomes of multimodal rehabilitation in primary care for patients with chronic pain. J Rehabil Med. 2020;52(2):1-10. https://doi.org/10.2340/16501977-2649.

34. Aasdahl L, Pape K, Vasseljen O, Johnsen R, Fimland MS. Improved expectations about length of sick leave during occupational rehabilitation is associated with increased work participation. J Occup Rehabil. 2018:1-8. https://doi.org/10.1007/s10926-018-9808-4.

35. Adams $\mathrm{H}$, Thibault $\mathrm{P}$, Ellis $\mathrm{T}$, Moore E, Sullivan M. The relation between catastrophizing and occupational disability in individuals with major depression: concurrent and prospective associations. J Occup Rehabil. 2017; 27(3):405-12. https://doi.org/10.1007/s10926-016-9669-7.

36. Gagnon CM, Stanos SP, van der Ende G, Rader LR, Harden RN. Treatment outcomes for workers compensation patients in a US-based interdisciplinary pain management program. Pain Pract. 2013;13(4):282-8. https://doi.org/10. 1111/j.1533-2500.2012.00586.x.

37. Scott W, Wideman TH, Sullivan MJ. Clinically meaningful scores on pain catastrophizing before and after multidisciplinary rehabilitation: a prospective study of individuals with subacute pain after whiplash injury. Clin J Pain. 2014;30(3):183-90. https://doi.org/10.1097/AJP. 0b013e31828eee6c.

38. Sullivan M, Adams H, Ellis T, Clark R, Sully C, Thibault P. Treatment-related reductions in catastrophizing predict return to work in individuals with post-traumatic stress disorder. J Appl Biobehav Res. 2017;22(1):e12087. https://doi.org/10.1111/jabr.12087.

39. Volker G, van Vree F, Wolterbeek R, van Gestel M, Smeets R, Köke A, et al. Long-term outcomes of multidisciplinary rehabilitation for chronic musculoskeletal pain. Musculoskeletal Care. 2017;15(1):59-68. https://doi. org/10.1002/msc.1141.

40. Asih S, Mayer TG, Williams M, Choi YH, Gatchel RJ. Does classification of chronic musculoskeletal disorder patients into psychosocial subgroups predict differential treatment responsiveness and 1-year outcomes after a functional restoration program? Clin J Pain. 2015;31(12):1036-45. https://doi. org/10.1097/AJP.0000000000000216.

41. Hees HL, Koeter MW, de Vries G, Ooteman W, Schene AH. Effectiveness of adjuvant occupational therapy in employees with depression: design of a randomized controlled trial. BMC Public Health. 2010;10(1):558. https://doi. org/10.1186/1471-2458-10-558.

42. Jensen AGC. Towards a parsimonious program theory of return to work intervention. Work. 2013;44(2):155-64. https://doi.org/10.3233/WOR-121496.

43. Rolving N, Oestergaard LG, Willert MV, Christensen FB, Blumensaat F, Bünger C, et al. Description and design considerations of a randomized clinical trial investigating the effect of a multidisciplinary cognitive-behavioural intervention for patients undergoing lumbar spinal fusion surgery. BMC Musculoskelet Disord. 2014;15(1):62. https://doi.org/10.1186/1471-2474-15-62.

44. Sullivan MJ, Adams H, Ellis T. A psychosocial risk-targeted intervention to reduce work disability: development, evolution, and implementation challenges. Psychol Inj and Law. 2013;6(3):250-7. https://doi.org/10.1007/ s12207-013-9171-X.

45. Hoefsmit N, Houkes I, Nijhuis FJ. Intervention characteristics that facilitate return to work after sickness absence: a systematic literature review. J Occup Rehabil. 2012;22(4):462-77. https://doi.org/10.1007/s10926-012-9359-z.

46. Petrie KJ, Weinmann J. Why illness perceptions matter. Clin Med. 2006;6(6): 536-9. https://doi.org/10.7861/clinmedicine.6-6-536.

47. Woodhouse S, Hebbard G, Knowles SR. Exploring symptom severity, illness perceptions, coping styles, and well-being in gastroparesis patients using the common sense model. Dig Dis Sci. 2018;63(4):958-65. https://doi.org/10. 1007/s10620-018-4975-X. 
48. Müssener U, Svensson T, Söderberg E, Alexanderson K. Encouraging encounters: sick-listed persons' experiences of interactions with rehabilitation professionals. Soc Work Health Care. 2007;46(2):71-87. https:// doi.org/10.1300/J010v46n02_05.

49. Müssener U, Ståhl C, Söderberg E. Does the quality of encounters affect return to work? Lay people describe their experiences of meeting various professionals during their rehabilitation process. Work. 2015;52(2):447-55. https://doi.org/10.3233/WOR-152121.

50. De Wit M, Horreh B, Daams JG, Hulshof CTJ, Wind H, De Boer AGEM. Abstract 12: Interventions on cognitions and perceptions that influence work participation of employees with chronic health problems: a scoping review. ICOH Abstracts. Indian J Occup Environ Med. 2020;24(Suppl S1):3-2.

\section{Publisher's Note}

Springer Nature remains neutral with regard to jurisdictional claims in published maps and institutional affiliations.

- fast, convenient online submission

- thorough peer review by experienced researchers in your field

- rapid publication on acceptance

- support for research data, including large and complex data types

- gold Open Access which fosters wider collaboration and increased citations

- maximum visibility for your research: over $100 \mathrm{M}$ website views per year

At BMC, research is always in progress.

Learn more biomedcentral.com/submissions 